\title{
BMJ Open How patient acceptability affects access to breast reconstruction: a qualitative study
}

\author{
Helene Retrouvey, ${ }^{\oplus 1}$ Toni Zhong, ${ }^{2}$ Anna R Gagliardi, ${ }^{3}$ Nancy N Baxter, ${ }^{4}$ \\ Fiona Webster ${ }^{5}$
}

To cite: Retrouvey H, Zhong T, Gagliardi AR, et al. How patient acceptability affects access to breast reconstruction: a qualitative study. BMJ Open 2019;9:e029048. doi:10.1136/ bmjopen-2019-029048

- Prepublication history and additional material for this paper are available online. To view these files, please visit the journal online (http://dx.doi. org/10.1136/bmjopen-2019029048).

Received 09 January 2019 Revised 10 August 2019 Accepted 13 August 2019

\section{Check for updates}

(c) Author(s) (or their employer(s)) 2019. Re-use permitted under CC BY-NC. No commercial re-use. See rights and permissions. Published by BMJ.

${ }^{1}$ Division of Plastic and Reconstructive Surgery, Department of surgery, University of Toronto, Toronto, Ontario, Canada

${ }^{2}$ Department of surgery, University Health Network, Toronto, Ontario, Canada ${ }^{3}$ Institute of Health Policy, Management and Evaluation, University Health Network, Toronto, Ontario, Canada ${ }^{4}$ Division of General Surgery, Department of Surgery, St. Michael's Hospital, Toronto, Ontario, Canada

${ }^{5}$ Faculty of Health Sciences, Arthur Labatt School of Nursing, Western University, London, Ontario, Canada

Correspondence to Dr Helene Retrouvey; helene.retrouvey@mail.utoronto. ca

\section{ABSTRACT}

Objectives There has been limited research on the acceptability of breast reconstruction (BR) to breast cancer patients. We performed interviews to explore breast cancer patients' acceptability of BR.

Design Qualitative study.

Setting Recruitment from six Ontario hospitals across the province (Toronto, Ottawa, Hamilton, London, Thunder Bay and Windsor) as well as key breast cancer organisations between November 2017 and June 2018.

Participants Women of any age with a diagnosis of breast cancer planning to undergo or having undergone a mastectomy with or without BR.

Intervention Sixty-minute semi-structured interviews were analysed using qualitative descriptive methodology that draws on inductive thematic analysis.

Outcome In the telephone interviews, participants discussed their experience with breast cancer and accessing BR, focusing on the acceptability of BR as a surgical option post-mastectomy.

Results Of the 28 participants, 11 had undergone BR at the time of the interview, 5 at the time of mastectomy and 6 at a later date. Four inter-related themes were identified that reflected women's evolving ideas about BR as they progressed through different stages of their disease and treatment. The themes we developed were: (1) cancer survival before BR, (2) the influence of physicians on BR acceptability, (3) patient's shift to BR acceptance and (4) women's need to justify BR. For many women, access to BR surgery became more salient over time, thus adding a temporal element to the existing access framework. Conclusion In our study, women's access to BR was negatively influenced by the poor acceptability of this surgical procedure. The acceptability of BR was a complex process taking place over time, from the moment of breast cancer diagnosis to BR consideration. BR access may be improved through enhancing patient acceptability of BR. We suggest adapting the current access to care frameworks by further developing the concept of acceptability.

\section{BACKGROUND}

Many women require mastectomy or the removal of the entire breast to treat breast cancer. ${ }^{2}$ Breast reconstruction (BR) aims to surgically restore the shape of the breasts after tumour removal and can be performed

\section{Strength and limitations of this study}

Qualitative research was performed as it allowed for in-depth exploration of barriers to access breast reconstruction (BR).

> Our manuscript focused on increasing our understanding of broad barriers to BR; it thus lacks a detailed review of specific barriers to immediate versus delayed BR and of autologous versus prosthetic-based BR.

- The sample size of the study was limited by our choice of qualitative methodology; despite this, we recruited a high number of participants for qualitative standards (above the recommended 12), achieved data saturation and interviewed 28 women of varying ages, with different breast cancer pathology from across the province to incorporate a wide variety of perspectives.

- We selected qualitative descriptive methodologies which encouraged the production of a manuscript with findings easily translated to clinical practice.

- Our choice of qualitative descriptive methodology limited the depth of interpretation, but the inclusion of mid-level theory and the congruence in onto-epistemology ensured rigour and quality of this manuscript.

at the same time (immediate BR (IBR)) or after mastectomy (delayed BR (DBR)). ${ }^{2}$ In Canada, general surgeons perform the mastectomy while plastic surgeons perform the reconstruction. ${ }^{3}$ BR can provide longterm quality of life and psychosocial benefits, improving the physical and psychological damage from mastectomy for women who chose this procedure. ${ }^{3-10}$ Despite its benefits for some women, studies have found that BR is not consistently integrated into treatment of breast cancer patients. ${ }^{31-16}$ In Canada, BR rates are low, reported as $16 \%$ in $2012 .{ }^{3}$ Rates are similarly low in Ontario, quoted at $7.6 \%$ between 2004 and 2010. ${ }^{3}$ While it is difficult to ascertain if these low rates are appropriate (ie, if they reflect the fact that mastectomy patients do not want BR), they certainly do 
not reflect the finding by Ananian et al that $81 \%$ of mastectomy patients would want BR if offered the choice. ${ }^{17}$

Access is defined by Penchansky and Thomas as the 'degree of fit between the users and the system'. ${ }^{18}$ Access may be reduced for BR due to patient/physician/systemlevel barriers. ${ }^{18}$ Studies have found that patient age and socioeconomic status, physician's beliefs and values, availability of plastic surgeons at institutions and geographic location are common barriers to BR access. ${ }^{36}{ }^{19-28}$ These factors act as barriers in the six access to care domains presented by Penchansky and Thomas, specifically availability, accessibility, awareness, affordability, accommodation and acceptability.

Acceptability has been poorly evaluated in the context of access to $\mathrm{BR}$, a preference sensitivity procedure. A 'preference sensitivity' procedure is a treatment where multiple options exist with heterogenous trade-offs. ${ }^{29}$ The published literature on BR acceptability only evaluates the association between patient factors, physician view and rates of BR. ${ }^{21} 2526$ 30-34 Certain patient characteristics have been associated with increased likelihood of BR discussion/referral by physicians; these included younger, more educated, English speaking, Caucasian patients with higher income. ${ }^{25-27} 33-38$ In Canada, immigrant women and women who live in neighbourhoods with lower median income have significantly lower odds of $\mathrm{BR} .{ }^{3}$ These highlight barriers to BR access despite universal healthcare coverage where all patients should have equal access to BR. ${ }^{36}{ }^{39}$ These studies denote potential acceptability barriers to BR access but fail to capture patient's opinions of the acceptability of this surgical procedure and how these may impact access to BR. Furthermore, the published literature does not evaluate the impact of gender on acceptability; women may feel hesitant to accept an additional surgery which would temporarily remove their ability to partake in activities. ${ }^{40-43}$ Given that the acceptability of BR by patients has not yet been examined, the purpose of our study was to conduct qualitative interviews with women to explore their experiences with $\mathrm{BR}$ and improve our understanding of this phenomenon. Qualitative research allowed for in-depth exploration of patient-level barriers and had the potential to increase our understanding of the role of patient acceptability in women's access to BR.

\section{METHODS}

\section{Approach}

The study is guided by the social constructivism paradigm and a qualitative descriptive methodology. ${ }^{45}$ Qualitative descriptive methodology is an inductive methodology which 'stays close to the data', facilitating the understanding of a selected phenomenon and generating practical and clinically applicable knowledge for healthcare providers. ${ }^{44} 4647$ We use the consolidated criteria for reporting qualitative research checklist to guide the reporting of this research to optimise rigour. ${ }^{48}$

\section{Sampling and recruitment}

Women with a diagnosis of breast cancer planning to undergo or having undergone a mastectomy were sampled purposively. We recruited patients from three groups: (1) not having undergone BR (no BR), (2) having undergone IBR or (3) DBR.

Plastic surgeons working at six centres across the province of Ontario (Toronto, Ottawa, Hamilton, London, Thunder Bay and Windsor) recruited, via telephone, breast cancer patients.

Plastic surgeons purposively selected breast cancer patients before or after their BR consultation for participation in the study. These patients were selected as they had the potential to generate information rich data, that is, they could provide detailed and meaningful perspectives on barriers to BR access. ${ }^{49}$ Convenience sampling was also used; poster advertisement was used to sample breast cancer patients involved with breast cancer organisations from across Ontario (Rethink Breast Cancer, Wellspring Cancer Support Network, Willow Breast Cancer Support Canada and the Canadian Breast Cancer Foundation).

Through these diverse recruitment strategies, we aimed to include women of varying sociodemographic backgrounds (age and income quintile) and geographical locations within the province of Ontario, Canada. ${ }^{50}$ Breast cancer patients who agreed to participate were then enrolled.

\section{Data collection}

Semi-structured individual telephone interviews were conducted by HR. The research team developed an interview guide thorough a detailed review of the literature and access to care frameworks (online supplementary appendix 1). ${ }^{18}$ The access to care framework by Andersen and Penchansky was used as mid-level theory in this study, providing a conceptual framework to define access. ${ }^{181-56}$ The interview guide was pilot tested and iteratively refined by HR to improve interview flow and add prompts. The guide was then consistently used during the interviews. The telephone interviews were conducted by HR (a clinician and graduate student) under the mentorship of FW (expert qualitative researcher). After informed consent was obtained, participants were asked to provide information on their age as well as reconstructive status before the interview. The interviews discussed women's experience with breast cancer, their views and opinions about BR and their experience trying to access BR. Telephone interviews were chosen as they generate similarly rich data to in-person interviews and allowed for feasible interviews of participants from across Ontario ${ }^{57-64}$ Interviews averaged 45-60 min in length. Interviews were audio recorded and transcribed verbatim. Interviews were conducted until saturation was achieved, and no new information was forthcoming. Saturation was reached at 20 interviews, but additional interviews with patients from a variety of geographical and clinical settings were conducted to ensure no new themes emerged as patients. 


\section{Approach to data analysis}

Our analysis was performed in a stepwise iterative fashion as described by Saldana, from the development of codes to the generation of themes. ${ }^{656}$ The first five interviews were independently reviewed and two authors (HR and FW) performed initial coding. These two investigators then met to compare codes, thus enabling the process to be reflexive as each author discussed their own perspectives and assumptions. Through a series of meetings and discussions, a coding framework was developed and HR applied second cycle coding to interviews as they were performed. ${ }^{6-69}$ The coding framework was revised as necessary based on new findings. Coding software was used to organise the data (NVivo V.12.0, QSR International). This process allowed for the development of preliminary categories and themes. These were shared with all members of the research team which independently reviewed the themes and, through discussion, refined them. All authors provided methodological and content expertise to ensure trustworthiness of the study. ${ }^{71}$ All authors critically reviewed the data and its interpretation to ensure confirmability as well as the analytical process to ensure rigour and congruence. We interpreted the meaning of the data through thematic analysis. 4472

\section{Patient and public involvement}

Patients were not involved in the design of this study; the research team will actively engage patients in the next phase of the study, the development of targeted interventions that address the acceptability barriers identified in this study.

\section{RESULTS}

Thirty-one women were approached to participate in the study and 28 women agreed to participate in the interviews (table 1). Three women selected not to participate because of the 1-hour time commitment required. Women were on average 49 years old. Patients were either waiting for a mastectomy (pending mastectomy (PM) - eight patients) or had undergone mastectomy (M-19 patients). Some patients underwent neoadjuvant or adjuvant chemo $(\mathrm{C}-13$ patients) or radiation $(\mathrm{R}-5$ patients) therapy. Of the 28 participants, 11 underwent BR with 5 at the time of mastectomy (IBR) and 6 in a delayed fashion (DBR). All participants who agreed to participate had some level of interest in BR. We identified four inter-related themes that reflected women's evolving ideas about the acceptability of BR as they progressed through different stages of their disease and treatment. These were: (1) cancer survival before BR, (2) the influence of physicians on BR acceptability, (3) patient's shift to BR acceptance and (4) women's need to justify BR (figure 1). Additional quotes are presented in table 2. The poor acceptability of BR by patients was found to be the main barriers affecting women's decision-making, and ultimately negatively impacted BR access (figure 2).

\section{Theme 1: cancer survival before BR}

Women in the study described their experience with breast cancer diagnosis and most reported significant distress on learning about their initial diagnosis. During this distressing period, women often could not consider BR as they were overwhelmed by their new diagnosis. Women were often shaken and traumatised by this information and described being surprised, shocked and angered with this unexpected and life changing diagnosis. One woman stated, 'Having cancer, it's like 1 day you're walking along and you think you're living your life and you're living it the best you can and you feel like you just get run over by a Mack truck, right? It's a pretty scary and daunting kind of event that transpires.' (ID 113-M, IBR). During this initial period, women were overwhelmed and experienced difficulty processing this diagnosis. Some women feared death, 'I just felt like I was full of cancer and I thought I was going to die' (ID 125-PM, no BR). This initial period was challenging for women; before women could start evaluating BR, they first needed to process their diagnosis.

During this process, many women focused only on treatments aimed at curing their breast cancer, avoiding thinking of other treatments such as BR that did not improve survival. Women reported not thinking about $\mathrm{BR}$ at that time, as only concern was to 'get the cancer out' (ID 115-M, C, no BR). Some women chose not to undergo $\mathrm{BR}$ at the time of their breast cancer surgery because it was seen as an optional surgery and was not perceived as an essential component of their oncological treatment plan. One participant noted, 'In order to get rid of the cancer, the chemo, the radiation, the surgery was needed, and the breast reconstruction is an option' (ID 110-M, chemoradiation (CR), no BR). Therefore, early in the journey of breast cancer, some patients focused on their cancer diagnosis and associated curative treatments, avoiding thinking of BR. The acceptability of BR only came to play once patients considered the option of BR.

\section{Theme 2: the influence of physicians on Br acceptability}

Women relied significantly on their physician to guide them through their breast cancer diagnosis and provide advice regarding the most appropriate treatment plan. A woman stated, 'I let him guide it, I let him guide it. Because at that point, when someone tells you, you have cancer, the person's voice all of a sudden turn into Charlie Brown's teacher, you know waa, waa, waa.' (ID 122-M, C, no BR). The physician's guidance regarding BR could influence the patient's acceptability of this surgical procedure.

The options presented by the physicians to the patients impacted their ability to consider BR. In the interviews, we noted a wide variation in how physicians communicated treatment options to patients. Some women reported that their physician 'laid out all kinds of options for (them)' (ID 107-M, DBR) and 'explaining everything in detail' (ID 130-M, IBR). A patient stated, 'I 
Table 1 Participant information

\begin{tabular}{|c|c|c|c|c|c|c|}
\hline ID† & Site* & Age (Years) & $\begin{array}{l}\text { Previous breast } \\
\text { cancer treatment }\end{array}$ & Current breast cancer treatment & $\begin{array}{l}\text { Breast reconstruction } \\
\text { received }\end{array}$ & $\begin{array}{l}\text { Type of } \\
\text { reconstruction }\end{array}$ \\
\hline 105 & 3 & $55-59$ & - & $\begin{array}{l}\text { Mastectomy, } \\
\text { adjuvant chemotherapy }\end{array}$ & Yes & DBR-autologous \\
\hline 106 & 3 & $40-44$ & $\begin{array}{l}\text { Lumpectomy, } \\
\text { adjuvant } \\
\text { chemoradiation }\end{array}$ & Mastectomy & Yes & IBR-prosthetic \\
\hline 107 & 3 & $55-59$ & Lumpectomy & Mastectomy & Yes & DBR-autologous \\
\hline 108 & 3 & $50-54$ & Lumpectomy & Mastectomy & Yes & IBR-prosthetic \\
\hline 109 & 3 & $65-69$ & - & $\begin{array}{l}\text { Mastectomy, } \\
\text { adjuvant chemotherapy }\end{array}$ & Yes & DBR-autologous \\
\hline 110 & 4 & $55-59$ & - & $\begin{array}{l}\text { Mastectomy, } \\
\text { adjuvant chemoradiation }\end{array}$ & No & \\
\hline 111 & 6 & $45-49$ & - & Mastectomy & Yes & DBR-prosthetic \\
\hline 112 & 1 & $60-64$ & - & Neoadjuvant chemotherapy, pending mastectomy & No & \\
\hline 113 & 3 & $50-54$ & Lumpectomy & Mastectomy & Yes & IBR-prosthetic \\
\hline 114 & 1 & $55-59$ & - & Neoadjuvant chemotherapy, pending mastectomy & No & \\
\hline 115 & 6 & $50-54$ & - & $\begin{array}{l}\text { Mastectomy, } \\
\text { adjuvant chemotherapy }\end{array}$ & No & \\
\hline 116 & 6 & $65-69$ & Lumpectomy & Mastectomy & Yes & DBR-prosthetic \\
\hline 117 & Organisation & $40-44$ & $\begin{array}{l}\text { Lumpectomy, } \\
\text { adjuvant } \\
\text { chemoradiation }\end{array}$ & Pending mastectomy & No & \\
\hline 118 & Organisation & $30-34$ & - & $\begin{array}{l}\text { Neoadjuvant chemotherapy, mastectomy, } \\
\text { adjuvant radiotherapy }\end{array}$ & No & \\
\hline 119 & Organisation & $40-44$ & - & $\begin{array}{l}\text { Mastectomy, } \\
\text { adjuvant chemoradiation }\end{array}$ & No & \\
\hline 120 & 1 & $55-59$ & & & - & - \\
\hline 121 & Organisation & $25-29$ & - & Neoadjuvant chemotherapy, pending mastectomy & No & \\
\hline 122 & 4 & $35-39$ & - & $\begin{array}{l}\text { Mastectomy, } \\
\text { adjuvant chemotherapy }\end{array}$ & No & \\
\hline 123 & 4 & $60-64$ & - & Neoadjuvant chemotherapy, pending mastectomy & No & \\
\hline 124 & 2 & $50-54$ & - & Pending mastectomy & No & \\
\hline 125 & 4 & $55-59$ & - & Pending mastectomy & No & \\
\hline 126 & 4 & $55-59$ & - & Pending mastectomy & No & \\
\hline 127 & 6 & $45-49$ & Lumpectomy & Mastectomy, adjuvant radiotherapy & No & \\
\hline 128 & 5 & $55-59$ & - & $\begin{array}{l}\text { Mastectomy, } \\
\text { adjuvant chemoradiation }\end{array}$ & No & \\
\hline 129 & 6 & $25-29$ & - & $\begin{array}{l}\text { Mastectomy, } \\
\text { adjuvant chemotherapy }\end{array}$ & Yes & DBR-prosthetic \\
\hline 130 & 5 & $25-29$ & - & Mastectomy & Yes & IBR-autologous \\
\hline 131 & 6 & $40-44$ & Lumpectomy & Mastectomy & Yes & IBR-prosthetic \\
\hline 132 & Organisation & $50-54$ & - & $\begin{array}{l}\text { Mastectomy, } \\
\text { adjuvant chemotherapy }\end{array}$ & No & \\
\hline
\end{tabular}

*Sites 1-4 are high volume centres. Sites 5 and 6 are small volume centres. †ID 100-104 were pilot test interviews to refine interviewing strategies.

DBR, delayed breast reconstruction; IBR, immediate breast reconstruction.

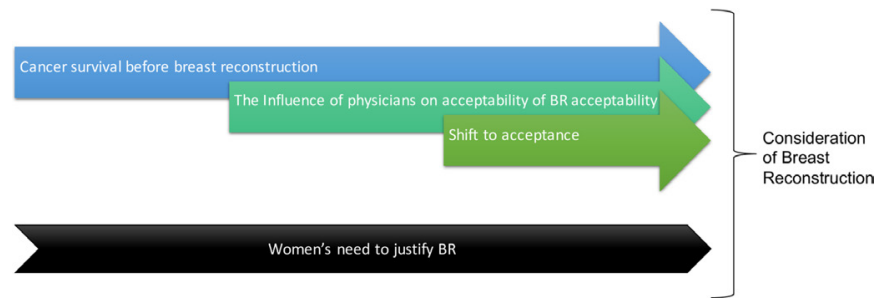

Figure 1 Acceptability barriers to access to breast reconstruction. was given a choice, you can either go this path with the lumpectomy with radiation or you can go this path with the mastectomy and no radiation. And it was totally up to me, there was no pressure to make a decision at the time' (ID 108, M, IBR). Other patients were not offered the options of BR by their surgeon. A participant reported, 'I wasn't given that option, okay, and I wasn't given that option. [...] I accepted that she, (the surgeon), said that, no, this is the process that will ... I didn't fight for ... I didn't say, no, I want reconstruction at the same time. 
Table 2 Table of supplementary quotes

\begin{tabular}{|c|c|c|}
\hline Themes & Sub-themes & Quotes \\
\hline \multirow[t]{4}{*}{$\begin{array}{l}\text { Theme } 1 \text {-cancer } \\
\text { survival before breast } \\
\text { reconstruction }\end{array}$} & $\begin{array}{l}\text { Surprised, shocked } \\
\text { by the diagnosis of } \\
\text { breast cancer }\end{array}$ & $\begin{array}{l}\text { 'I mean, I didn't know what I was walking into. I mean, the first two weeks I thought I was going to die because that's how } \\
\text { little I knew about cancer.' (ID 106, M, IBR) } \\
\text { 'Sometimes having breast cancer is a major trauma in your life, right? Having cancer, it's like one day you're walking } \\
\text { along and you think you're living your life and you're living it the best you can and you feel like you just get run over by a } \\
\text { Mack truck, right? It's a pretty scary and daunting kind of event that transpires, certainly for me.' (ID 113, M, IBR) }\end{array}$ \\
\hline & $\begin{array}{l}\text { Overwhelmed by the } \\
\text { diagnosis }\end{array}$ & $\begin{array}{l}\text { 'I think my initial reaction to the diagnosis was shock, anger, sadness, complete and utter confusion because when I } \\
\text { found the lump, I'm like, oh, it's nothing. I have very large breasts, and I just assumed it was just lumps. They came and } \\
\text { went, and I have no family history so I was completely gobsmacked. So, I think I was in a bit of a tailspin. I didn't really } \\
\text { know whether I was coming or going. I knew nothing about breast cancer.' (ID 117, PM) } \\
\text { 'I went by myself to the general surgeon and I basically told him that he was talking French to me. I didn't understand any } \\
\text { of his medical terminology and I just looked at him and said so you're telling me I have breast cancer and he said yes. } \\
\text { It was kind of a blur after that. I just came home and felt quite empty and then got in contact with my kids and basically } \\
\text { told them that we had to have a little family meeting and we all cried. At that point I didn't know what stage I was at. Any } \\
\text { little pain even in my back or anything I just felt like I was full of cancer and I thought I was going to die.' (ID 125, PM) }\end{array}$ \\
\hline & $\begin{array}{l}\text { Focus on cancer } \\
\text { survival }\end{array}$ & $\begin{array}{l}\text { 'At one time I remember saying to the surgeon, telling him "I'm the kind of person who knows my own mind". I'm pretty } \\
\text { clear that at this stage in my life like a breast deformity or a no breast is not really that important to me. But what is } \\
\text { important to me is that I completely eliminate any risk of cancer and that's possible by doing it, by having a mastectomy.' } \\
\text { (ID } 107, \mathrm{M} \text {, DBR) } \\
\text { 'So, for me, researching reconstruction, like, my mom was talking about it early on and I had to say, look, I have to get } \\
\text { through chemo, I have to get through mastectomy, I have to get through radiation, I don't even want to think about } \\
\text { reconstruction until I'm close to that being a possibility.' (ID } 119, \mathrm{M}, \mathrm{CR} \text { ) }\end{array}$ \\
\hline & $\begin{array}{l}\text { BR not always seen } \\
\text { as part of breast } \\
\text { cancer treatments }\end{array}$ & $\begin{array}{l}\text { 'The other, to me, again, from my perspective, is that the others weren't options. In order to get rid of the cancer, the } \\
\text { chemo, the radiation, the surgery were needed, and the breast reconstruction is an option. It's available, it's out there, } \\
\text { there's wonderful surgeons, there are amazing things that they can do, but it's truly an option. It's like cosmetic surgery, } \\
\text { it's totally an option, but again, information totally available and more than willing to go into the discussion, etcetera, with } \\
\text { you over breast reconstruction.' (ID 110, M, CR) } \\
\text { 'It's almost like it's ... it is like a treatment for the cancer, but in a way it's not. It's sort of almost like it's ... I want to say } \\
\text { it's separate, but in a way it is because I almost don't associate that with the cancer itself. This is just something I'm } \\
\text { doing for me, to make myself feel better. But I don't really associate ... I know that's why I need it is because I had the } \\
\text { cancer, but I don't really associate it almost as a treatment, if you understand what I'm getting at.' (ID 111, M, DBR) }\end{array}$ \\
\hline
\end{tabular}

Theme 2-the Reliance on influence of physicians physician guidance on BR acceptability
'I let him guide it, yeah, I let him guide it. Because at that point, when someone tells you, you have cancer, the person's voice all of a sudden turns into Charlie Brown's teacher, you know waa, waa, waa. You just kind of nod, and try not to lose your marbles right there in the room.' (ID 122, M, C)

'I knew nothing about breast cancer. Then when I was actually in the meeting with my doctor at the community Hospital $\mathrm{Y}$, the surgeon who gave me the results from the biopsy that they did at that point said we could do a lumpectomy or a mastectomy.' (ID 117, PM)

Variability of options 'I was given a choice, you can either go this path with the lumpectomy with radiation or you can go this path with the presented by physician mastectomy and no radiation. And it was totally up to me, there was no pressure to make a decision at the time.' (ID 108, $\mathrm{M}, \mathrm{IBR})$

'I've said, the surgeon went through all the options, told me surgically what happens with all the options, told me ... went through recovery time, what happens there, what probably treatments I would need after that.' (ID 111, M, DBR) 'So, she didn't push me one way or the other, she [surgeon] kind of gave me the facts and the research, statistics.' (ID 126, PM)

'No, we didn't really discuss pros and cons and she didn't really discuss pros and cons of the surgery with me. She discussed the two options. She basically said that there were two options. She also did say that if we did a lumpectomy and when they were doing the surgery if there was something that she couldn't do, then they would remove the breast and that's fine.' (ID 114, C, PM)

'I wasn't given that option, okay, and I wasn't given that option.(...)I accepted that she, [the surgeon], said that, no, this is the process that will ... I didn't fight for ... I didn't say, no, I want reconstruction at the same time. I accepted, I accepted that her recommendation and the process for me to follow was the process for me to follow.' (ID 110, M, CR)

Options of BR
'But actually, my surgeon actually said it's easier to recover from if you get them ... get the surgery done first, and then get the reconstruction done later.' (ID 111, M, DBR)

'Yeah, she [breast surgeon] was very, very adamant to say that. Don't worry, yes, you get a mastectomy, this is what happens, but you get a reconstruction, it's covered.' (ID 121, C, PM)

'I've said, the surgeon went through all the options, told me surgically what happens with all the options, told me .... went through recovery time, what happens there, what probably treatments I would need after that. It was ... and then mind you, I did ask him what his opinion was, I said, if it was your wife, what would you do. He said, the mastectomy, so I was like, okay, well, that's what I was thinking, too.' (ID 111, M, DBR)

'He said that we'll talk about it later, so he did not give me any information about reconstruction at that time.' (ID 109, M, C, DBR)

'Then the reconstructive, I had thought about it when I was told I could have it, and I could have it for free, I thought about it then. But I had asked my oncologist again, and he had said, you know what, why do you want it. I said, well, every female always has one bigger than the other anyway, and of course, where I got my cancer, had to be the smaller one anyway, which was annoying. When they take a lump out, as you know, you have to take tissue around it, so that took even more tissue. I thought about it, and then he had mentioned that if I did get reconstructive, that it might be harder to find behind the breast wall afterward. So, I just said, you know what, forget it for now.' (ID 122, M, C) 
Table 2 Continued

\begin{tabular}{lll}
\hline Themes & Sub-themes & Quotes \\
\hline Theme 3-patient's & BR as regaining & 'For me it was just again part of my whole psyche I think was about, there is a tactile or practical element that enabled
\end{tabular}
$\begin{array}{ll}\text { Theme } 3-\text { patient's } & \text { BR as regaining } \\ \text { shift to acceptance } & \text { control }\end{array}$
Theme 4-women's need to justify BR me to feel that perhaps I had some measure of control in a situation that I really had no control over. I had no control over what the test results were going to show up. I had no control over how I was going to react to chemo. There's so much about it you have no control over. Whereas sometimes if you make a decision, it feels like you've got some measure of control for some people. But that's good, right? You don't feel like everything is spiralling on you.' (ID 113, M, IBR) 'That's about the only time you have control, okay. Like, during chemo, you do not have control, doing radiation, you do not have control, it's just a process you have to go through. During surgery, you have control. That's how I look at it. I mean, yes, you could turn down chemo, you could turn down radiation, you could, okay, there is control a little bit, but what I mean by that, the outcome of that is potentially death by not doing it, or a higher likelihood of death because the mass was just going to keep on growing. So, yeah, in a sense, you do have a little bit of control, but if your whole thing is that you want to get rid of the cancer, you have to go through those steps.' (ID 110, M, CR)

'For me, it's just kind of just a bit of an F-U to cancer. Like, I'm going to get that back, and I'm not going to look in the mirror every day and see what I see, which is cancer took that from me. So part of it is, you know, a bit of a mental thing that l'm not going to let cancer deform my body, l'm not going to look in the mirror and see what used to be is no longer there because of cancer. I mean, for me that's part of it. Just kind of regaining control and having my body back. So that's a big part of a motivating factor for having it done.' (ID 119, M, CR)

Closure through BR 'But to me, having the reconstruction was, and that's hard to explain to everybody when people were asking me, I would say, that's the last step, that's the final step, is the repair of all the damage that has been done over the last twoyears. It's like, for me it's like, okay, let's repair this and then I can move on with my life.' (ID 111, M, DBR) 'It's like, okay, well, now it's time to make me completely healthy. It's almost like it's a .... the next ... almost like closing a door, kind of. You can close your door, and then get on with the rest of your life. This ... the whole last two years will finally be over. Not the nightmare, but you know what I mean?' (ID 111, M, DBR)

'But I also looked upon it as sort of a way to move forward past the cancer diagnosis and further into my life after cancer in a hopeful way. It was like a statement to myself that we're going to continue on and do the best we can with this.' (ID 128, M, CR)

'I think it's really good because you're getting something taken away but at the same time, you're given something, an opportunity to have some type of breast back. So, they're going to take away the cancer cells that are there because if we don't, it could kill us. But having that opportunity to have breasts back and to be able to feel more normal and cancer free but yet have my woman ... my breasts, things I identify with, to have that just is, to me, is a much easier process mentally for me.' (ID 126, PM)

'Having or not having a breast is [a matter of debate] ... I could live either way and then the whole aspect around vanity. I don't know how people consider sort of having a breast or not having a breast whether it's just a cosmetic aspect or not, different people's views. There's sort of a wide range of views. I think for young women having your breasts is really, really important. It's part of their sense of self and body image and there's a lot of things. I think when you're older you may have a different sort of view of it. I mean there's this whole aspect around any body part. If you lost a body part, any other body part, it's got to both function and there's this aesthetic aspect to it so you got to consider both of those things. But then with the breast maybe there's this other aspect around sexuality, function sort of piece that's built into it. I don't know. Different people have different perspectives about how important a breast is.' (ID 107, M, DBR)

'There's also the barrier in terms of, and I've sort of had to deal with this a little bit, there may be perceptions out there that this is sort of an undeserving use of healthcare resources, that's number one. Number two, sort of the risking surgery ... all the risks that are associated with surgery for what could be considered just cosmetic reasons, that sort of piece.(...) There's people who have a bias, they're like I would never do that. I would never risk my health over something so trivial as having a breast. People who have those biases ... I mean you have some of that awareness that there are people who could think this way and you have to ... if this is a decision that you've made you have to be strong in your resolve. Maybe not all women are as ... they could be more influenced by those biases, prejudices, of views that are out there.' (ID 107, M, DBR)

'I know everybody thinks, well, just, why is it a big deal. It's like, well, for me, it is a big deal because that's what makes me ... to me, that's what makes a woman a woman, in a way.' (ID 111, M, DBR)

'The mastectomy, they all understood why I wanted to get the mastectomy. Actually they all said, oh, I would do that, too, if that was me. Reconstruction, Like I said, they ... I don't think a lot of them understand exactly what it is for reconstruction. They don't ... like I said, they've all said to me, oh, you don't need it, you're okay. But it's like, they don't understand the psychological part of it. Because I guess they think it ... to them it's like, no big deal. But it's like, it is a big deal. Unless you've been in that situation, it's... you don't understand it. Like I said, the best way I can explain it, you don't feel like you're a full person anymore.' (ID 111, M, DBR)

'I think they have thoughts, maybe, of breast reconstruction and then they decide, you know what, being flat is not such a bad thing after all. The initial shock of seeing it, there's one thing, but then, true of so many things in life, you just get used that's the way it is. I guess no different than if someone loses a limb, they also look at, do I want another limb, or a fake limb, or do I just go without? That's what I would say.' (ID 110, M, CR)

'To me it was a very personal choice. It's almost like what if somebody, if a woman wants to have an abortion or not, she's not going to ask everybody around because there's too many controversies and so it's really a very personal issue. So, to me, the breast reconstruction was as personal an issue as if I had to choose whether to have an abortion or not.' (ID 105, M, C, DBR)

'Well, it's ... reconstruction is more on how you feel. It's going to give you a sense of, it's just feel good about yourself. It's the same way when you dress up, and you feel, oh, I really like this dress, I feel good about it, even if some people think it's gross.' (ID 112, C, PM)

'Most people say that I'll get a free boob job, I'll get an upgrade on my breasts and the fact that l'm going to opt for the DIEP is going to be a bonus, that l'll have a tummy tuck all thrown into one.(...)And when they say things like, you'll get an upgrade, free plastic surgery, or whatever, I just remind them that it is not plastic surgery it's reconstruction.' (ID 118 C, M, R)

BR, breast reconstruction; C, chemotherapy;CR, chemoradiation; DBR, delayed breast reconstruction; IBR, immediate breast reconstruction; M, mastectomy;PM, pending mastectomy; R, radiation therapy.

I accepted, I accepted that her recommendation and the process for me to follow was the process for me to follow' (ID 110, M, CR). Another added, 'If that would have been an option for me, I would have done it then. But, that was not even mentioned' (ID 115-M, C, no $\mathrm{BR})$. Hence, if BR was not discussed or recommended 


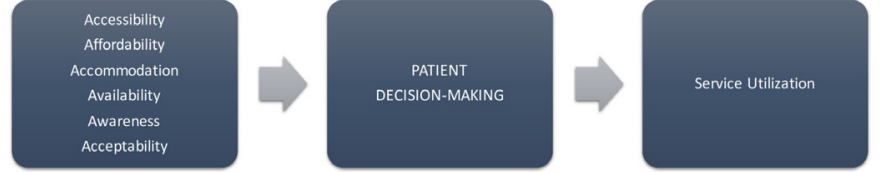

Figure 2 Dynamic nature of access: transition from access domains to patient decision-making to service utilisation.

by physicians, patients did not consider it as an option in their treatment plan.

When looking specifically at BR, the physician's views and opinions of this surgical procedure as well as the timing of discussion influenced patient's ability to select the option of IBR or DBR. In our interviews, patients' descriptions of the discussion of BR by breast surgeon varied widely, in some cases discussions were brief, '(the surgeon) didn't really discuss pros and cons of the surgery with me' (ID 114-C, PM, no BR), while others described lengthy and detailed discussions, '(the surgeon) went through all the options there was to do' (ID 111-M, DBR). Also, physicians offered their opinion on the procedure, encouraging or dissuading patients from seeking BR. One patient reported that her breast surgeon was very adamant to say, 'Don't worry, yes, you get a mastectomy, [...] but you get a reconstruction' (ID 121-C, PM, no BR). Another patient reported that her oncologist said that the detection of cancer recurrences is more difficult after BR, leading the patient to 'forget (the option of BR) for now' (ID 122-M, C, no BR). Patients offered BR by their physician were more likely to consider integrating BR in their breast cancer treatment plan. Thus, physicians who had positive views of BR and who integrated BR in the oncological treatment plan had a positive influence on the patient's acceptability of BR.

\section{Theme 3: patient's shift to BR acceptance}

\section{BR as regaining control}

While each patient had a unique experience with cancer, women were similar in that they perceived that they had no control over their breast cancer. Women could not predict their diagnosis and had limited influence on the most appropriate curative treatments offered, but they had control on the receipt of BR. One woman stated, 'I had some measure of control in a situation that I really had no control over' (ID 113-M, IBR). She added, 'Whereas sometimes if you make a decision, it feels like you've got some measure of control for some people. But that's good, right? You don't feel like everything is spiralling on you.' If BR was seen positively as offering control, it could be perceived to be an acceptable option by patients.

Women felt they could actively participate in the process of $\mathrm{BR}$, being able to voice their opinion on when to undergo BR. One woman commented that it was the element of decision that made her feel in control. Women viewed positively this feeling of control as it allowed them to feel empowered. A participant stated, 'I'm not going to look in the mirror every day and see what I see, which is cancer took that from me. So part of it is, you know, a bit of a mental thing that I'm not going to let cancer deform my body, I'm not going to look in the mirror and see what used to be is no longer there because of cancer. [...] Just kind of regaining control and having my body back' (ID 119-M, CR, no BR). Therefore, during the process of $\mathrm{BR}$, women felt they were in control and felt empowered with the ability to choose to undergo a surgery which could bring their pre-breast cancer 'body back'. As women realised that BR was a way of regaining control, this surgical procedure gained acceptability.

\section{Closure through BR}

BR not only allowed women to feel in control, it was often seen as the final step in their breast cancer journey. A participant noted, 'I had the surgery, I had the cancer removed, I had the treatments to make sure it won't come back and then now, I have the reconstruction' (ID 105-M, C, DBR). As the final step in the breast cancer path, BR was an option that could 'repair (the) damage' caused by the various breast cancer treatments.

In addition to 'repairing the damage' of breast cancer, BR often helped women feel better after a period of difficult treatments. BR was an opportunity for women to '(get) back' what they had lost from their breast cancer. A participant valued BR because, 'having the opportunity to have, I think for it to give you back something that cancer has taken from you, I think there's value to that' (ID 119-M, CR, no BR). Another women stated, 'But to me, having the reconstruction was, and that's hard to explain to everybody when people were asking me, I would say, that's the last step, that's the final step, is the repair of all the damage that has been done over the last 2 years. It's like, let's repair this and then I can move on with my life.' She added, 'It's like, okay, well, now it's time to make me completely healthy. It's almost like closing a door. You can close your door, and then get on with the rest of your life' (ID 111, M, DBR). BR helped women transition from the breast cancer chapter of their lives to their survivorship period. As one woman stated, 'But I also looked on it as sort of a way to move forward past the cancer diagnosis and further into my life after cancer in a hopeful way' (ID 128-M, C, no BR). Thus, women who viewed BR as offering the opportunity for closure had an increased acceptability of this surgical procedure.

\section{Theme 4: women's need to justify BR}

One pervasive theme that spanned throughout the interview was women's need to justify BR. Women's need to repeatedly justify their desire to undergo BR highlighted a lack of BR acceptability. In their justification, women discussed the need for breasts and the role of a surgery to recreate them. A participant stated, 'Having or not having a breast is (a matter of debate) ... I could live either way and then the whole aspect around vanity' (ID 107-M, DBR). Women worried that choosing BR was vain, 'I'm not looking for reconstructive to ... so I can strut around topless, you know what I mean, that's not it... it's not for 
vain reasons' (ID 122-M, C, no BR). Therefore, the acceptability of BR was affected by the worries women experienced when considering a surgery perceived to promote vanity.

Women used vivid metaphors and comparisons in their justification of BR. Women compared the loss of breast to the loss of another body part, debating the need for breasts, their function in the female body, and the role of a surgery to recreate them. A woman compared the option BR to options available after the loss of a limb, 'It would be like removing a leg, I guess. You need to have that leg. How do you feel if that leg wasn't there and you put a prosthesis there? Probably that's more extreme, but you know, that leg mean anything to you?' (ID 114-C, PM, no BR). The vivid metaphors depicted women's need to justify BR and highlighted that women sometimes felt misunderstood in their rationale for wanting the surgery. Women's need to continually justify BR suggested poor acceptability of this procedure by patients themselves and their surroundings.

Many women did not seem to be able to state that breasts were important to them and that they could undergo, without judgement, a reconstructive surgery to recreate them. A participant stated, 'It took me a while, but then I finally decided ... I needed it for me' (ID 111-M, DBR). Women were constantly justifying to themselves and to their surroundings that they 'needed' or 'deserved' BR. A participant reported that she found it difficult to express the desire for BR, stating 'I'm having a hard time saying this, but I came to the realisation that by having a reconstruction that I deserved it. I guess that's my sort of thing, that I deserved to have breasts and to feel more feminine'. She added, 'There's also the barrier in terms of, and I've sort of had to deal with this a little bit, there may be perceptions out there that this is sort of an undeserving use of healthcare resources' (ID 107-M, DBR). Women thought the choice to undergo BR was a 'very personal decision'; a choice that only they, as breast cancer patients, could fully understand. A participant said, 'I know everybody thinks, well, just, why is it a big deal. It's like, well, for me, it is a big deal because that's what makes me ... to me, that's what makes a woman a woman, in a way' (ID 111, M, DBR). The constant need for justification of women's choice to undergo BR highlighted the tension that some patients experienced when considering BR, which may be related to perceived external disapproval and/or lack of acceptance of a procedure aimed at recreating breasts.

Women were also conflicted when considering undergoing an additional 'optional' 'cosmetic' surgery to recreate their breasts, a procedure which would temporarily make them unable to perform their usual roles (ID 118-no BR). Women worried that the well-being of their surroundings would be compromised during their absence. Another women, who the main caregiver in the house, had to offload this responsibility onto others prior to undergoing surgery; she stated that there had to be a 'reversal of roles' (ID 112-no BR). Specifically, she reported, 'You know how it is, the mothers are always in charge of the house. Now I'm not in charge of the house, they're in charge'. Women thus faced challenges when thinking of undergoing BR, a procedure which would render them incapable of performing their usual roles. Therefore, the acceptability of BR was affected by the worries women experienced when considering a surgery perceived to promote vanity while also impairing women's ability to perform their traditional roles.

\section{DISCUSSION}

Our interviews with breast cancer patients highlighted a novel barrier to BR access in the universal Canadian healthcare system, the acceptability of this surgical procedure by patients. As BR is a preference-sensitive decision, an important aspect of access experienced by our interviewees was their perception of the acceptability of the surgical procedure. Our qualitative research also emphasised the dynamic and temporal nature of access to BR, with barriers present from diagnosis of breast cancer to receipt of BR. Patients first needed to process their life changing diagnosis of breast cancer before considering the different treatment options available to them. During this process, they relied heavily on physician recommendations in terms of the next steps. Patients who valued BR saw it as regaining control and as the final step in their cancer journey. During this process, women repeatedly justified their decision to consider BR, highlighting that some women felt that undergoing a surgery to recreate breasts may not be acceptable to themselves or their surroundings. Access to BR was therefore a complex process taking place over time with multiple factors affecting patients' acceptability of the procedure, including patient themselves, their immediate surrounding and healthcare professionals.

The well-accepted access to care frameworks by Penchansky and Thomas as well as Andersen has a limited description of acceptability. ${ }^{18}{ }^{51}$ As highlighted in our findings, our study indicated that these frameworks do not capture all elements of acceptability. We hypothesise that this may be related to the fact that these frameworks were not developed for access to preference sensitivity procedure. These frameworks assume that the nature of the procedure is acceptable; that patients are looking to access a service after the decision has been made that the procedure is needed. We propose adapting the two frameworks by emphasising the concept of acceptability in the context of preference sensitivity procedures such as $\mathrm{BR}$, to include individual and societal values of the health problems and its associated treatments.

In relation to this need to justify BR, social values around female gender roles may have informed participants' experience in our study and created tension for women considering BR. Many women in our interviews accepted gender roles of being responsible for the wellbeing of their surroundings, rather than caring solely for themselves. ${ }^{40-43} 74-76$ Women reported feeling a sense of discomfort when thinking about taking time to care 
for oneself. Similarly, in other fields, women report this feeling of guilt when deciding to undergo a procedure which may take time away from their traditional household duties. ${ }^{40778}$ The repeated justification of our participants towards their decision to pursue BR may highlight the gendered nature of acceptability. Furthermore, in our interviews, many women believed that valuing breasts and having surgery to improve their feminine identity reflected a superficial female vanity and was therefore not necessary or 'optional'. ${ }^{79}$ At the same time, many women described not feeling 'whole' or feminine without breasts. Perhaps as reflective of this tension, women who opted for BR felt they needed to justify their rationale for wanting this procedure. Other authors have described the benefits of BR for some women, allowing them to feel 'normal', whole or feminine again, but have not previously reported acceptability concerns. ${ }^{32} 8081$ Societal gender roles may therefore have influenced women's views of the acceptability of $\mathrm{BR}$, a surgical procedure aimed at recreating breasts. ${ }^{81}$ These findings suggest that gender may play a role in access to certain procedures.

The Penchansky and Andersen frameworks present access as a static concept, whereas access was seen as a dynamic process in our study. Through discussions with breast cancer patients, access to BR was found to evolve over time from the moment of breast cancer diagnosis to the receipt of $\mathrm{BR}$ and issues were different for patients seeking IBR and DBR. For some women, this process was short with minimal barriers, while for others the process was lengthy and, in many cases, evolved over time. Similarly, authors have noted that access is a dynamic process which balances patient need and service provision. ${ }^{82}$ Access to care frameworks should be revised to illustrate the everchanging concept of access as patients move through their care pathway.

Currently, access is measured through assessment of referral patterns and rates, availability of services, wait times or waitlists and rates of utilisation of a procedure ${ }^{83-87}$ However, wait times or waitlists and rates of utilisation may not accurately measure BR access as they do not account for individual patient opportunity and preference ${ }^{5287}$ Rates of utilisation may not be appropriate to measure access for preference-sensitive care, as a low rate of utilisation may not reflect poor access but instead may reflect patient preference or acceptability. Thus, some of the current measures of access do not allow for accurate measurement of BR access. Future research should address this limitation; without proper measurement, interventions cannot be designed to improve access to care.

Practically, our findings suggest that the pathway to accessing BR can be improved through enhancing the acceptability of BR by patients. From the moment of the initial breast cancer diagnosis, patients could benefit from support to mitigate the distress they experience. ${ }^{88} 89$ This support system should ensure that women are given the opportunity to access all treatment options for breast cancer including IBR and DBR, as appropriate based on their pathology. Tools such as the BRECONDA could be effective in providing decisional support during this process. ${ }^{90}$ Healthcare providers should also present BR as a valuable option in the breast cancer pathway. ${ }^{88}$ This could be achieved through enhanced buy-in from oncologists, including surgical oncologists (which usually perform the cancer resection surgery), which would help patients consider BR as an acceptable option. Women should be encouraged to explore their physical, emotional and spiritual well-being and the role BR may play for them. ${ }^{89}$ Throughout this process, by optimising the acceptability of the option of BR, women could select in an informed manner a treatment plan which may or may not include BR that best fits their desires and needs. ${ }^{89} 91$ Ensuring that patients and providers consider BR as an acceptable part of care for women with breast cancer will likely improve access to BR; future research is needed to evaluate this hypothesis.

Our study is limited by the population interviewed, specifically, the inclusion of women considering BR. Although our sampling strategy aimed to recruit a diverse sample of women with breast cancer having or not undergone BR, all women in our study thought about BR and considering undergoing it. Despite this limitation, our study was able to identify the acceptability barriers to BR access, which are likely reflective of the general breast cancer population. This study is limited by the lack of detailed review of specific barriers to IBR versus DBR and of autologous versus prosthetic-based BR. However, our focus in this exploratory study was to increase the understanding of broad barriers to BR access, acknowledging that these may not be applicable to all subtypes of BR. Future research should aim to refine the understanding of barriers to specific types of BR. Our study is also limited by the assumption that low rates of utilisation of BR in Ontario are attributed to existing barriers to access BR. Although we do not know the most appropriate rate of receipt of $\mathrm{BR}$, our interviews highlight that patients seeking BR experience acceptability barriers to access.

In conclusion, our interviews with breast cancer patients revealed that the acceptability of BR by patients influenced access to this surgical procedure. The acceptability of BR was dynamic as it evolved over time, from cancer diagnosis to consideration of BR. Although BR was viewed positively by some women as giving control and as providing closure, participants repeatedly justified their desire to undergo this procedure, highlighting the presence of acceptability barriers to BR access. This also potentially illustrates the interplay between gender roles and women's acceptability of BR. Improving access to BR needs to consider the important role of patient acceptability of surgery on access to care for progress to be made.

Acknowledgements We would like to acknowledge the contributions of Dr Jing Zhang, Dr Chris Doherty, Dr Ronen Avram, Dr Sanjay Azad and Dr Kristina Lutz for helping with recruitment. We would like to thank breast cancer organisations (Rethink Breast Cancer, Wellspring Cancer Support Network, Willow Breast Cancer 
Support Canada and the Canadian Breast Cancer Foundation) for helping with patient recruitment.

Contributors HR: substantial contributions to study conception and design; manuscript drafting; final approval of version to be published; agreement to be accountable for all aspects of the work. NNB and FW: substantial contributions to study conception; critical review of study content; final approval of version to be published; agreement to be accountable for all aspects of the work. ARG and TZ: substantial contributions to study conception and design; critical review of study content; final approval of version to be published; agreement to be accountable for all aspects of the work.

Funding The sponsors provided financial support to conduct the study and peer reviewed the project proposal, but were not involved in data collection, analysis or interpretation. TZ is the Belinda Stronach Chair in Breast Cancer Reconstructive Surgery of University Health Network and the recipient of the Canadian Institutes of Health Research (CIHR), Foundation Scheme Live Pilot. HR is supported by the Canadian Graduate Scholarship from the CIHR to pursue this research. Support from the Clinical Outcome Study Grant, Canadian Society of Plastic Surgeons and the Resident Research Grant, Physicians' Services Incorporated Foundation was also received. FW is partially supported in this work by a New Investigator Award from the CIHR.

Competing interests None declared.

Patient consent for publication Not required.

Ethics approval Institutional ethics board approval was obtained from the University of Toronto.

Provenance and peer review Not commissioned; externally peer reviewed.

Data availability statement Data are available upon reasonable request.

Open access This is an open access article distributed in accordance with the Creative Commons Attribution Non Commercial (CC BY-NC 4.0) license, which permits others to distribute, remix, adapt, build upon this work non-commercially, and license their derivative works on different terms, provided the original work is properly cited, appropriate credit is given, any changes made indicated, and the use is non-commercial. See: http://creativecommons.org/licenses/by-nc/4.0/.

\section{REFERENCES}

1. McDonald ES, Clark AS, Tchou J, et al. Clinical diagnosis and management of breast cancer. J Nucl Med 2016;57(Suppl 1):9S-16.

2. Senkus E, Kyriakides S, Ohno S, et al. Primary breast cancer: ESMO clinical practice guidelines for diagnosis, treatment and follow-up. Ann Oncol 2015;26(Suppl 5):v8-30.

3. Zhong T, Fernandes KA, Saskin R, et al. Barriers to immediate breast reconstruction in the Canadian universal health care system. JCO 2014;32:2133-41.

4. Schmauss D, Machens H-G, Harder Y. Breast reconstruction after mastectomy. Front Surg 2015;2.

5. Platt J, Baxter N, Zhong T. Breast reconstruction after mastectomy for breast cancer. Can Med Assoc J 2011;183:2109-16.

6. Barnsley GP, Sigurdson L, Kirkland S. Barriers to breast reconstruction after mastectomy in nova Scotia. Can J Surg 2008;51:447-52.

7. Cordeiro PG. Breast reconstruction after surgery for breast cancer. $N$ Engl J Med 2008;359:1590-601.

8. Zhong T, McCarthy C, Min S, et al. Patient satisfaction and healthrelated quality of life after autologous tissue breast reconstruction: a prospective analysis of early postoperative outcomes. Cancer 2012;118:1701-9.

9. Brandberg Y, Sandelin K, Erikson S, et al. Psychological reactions, quality of life, and body image after bilateral prophylactic mastectomy in women at high risk for breast cancer: a prospective 1-year follow-up study. JCO 2008;26:3943-9.

10. Wilkins EG, Cederna PS, Lowery JC, et al. Prospective analysis of psychosocial outcomes in breast reconstruction: one-year postoperative results from the Michigan breast reconstruction outcome study. Plast Reconstr Surg 2000;106:1014-25. discussion 26-7.

11. Morrow M. Factors influencing the use of breast reconstruction postmastectomy: a national cancer database study. J Am Coll Surg 2001;192:1-8.

12. Retrouvey H, Solaja O, Gagliardi AR, et al. Barriers of access to breast reconstruction: a systematic review. Plast Reconstr Surg 2019;143:465e-76.
13. Al-Ghazal SK, Sully L, Fallowfield L, et al. The psychological impact of immediate rather than delayed breast reconstruction. Eur J Surg Oncol 2000;26:17-19.

14. Rubino C, Figus A, Lorettu L, et al. Post-Mastectomy reconstruction: a comparative analysis on psychosocial and psychopathological outcomes. J Plast Reconstr Aesthet Surg 2007;60:509-18.

15. Kraus PL. Body image, decision making, and breast cancer treatment. Cancer Nurs 1999;22:421-7. quiz 28-9.

16. Figueiredo MI, Cullen J, Hwang $\mathrm{Y}-\mathrm{T}$, et al. Breast cancer treatment in older women: does getting what you want improve your long-term body image and mental health? JCO 2004;22:4002-9.

17. Ananian $P$, Houvenaeghel $G$, Protière $C$, et al. Determinants of patients' choice of reconstruction with mastectomy for primary breast cancer. Ann Surg Oncol 2004;11:762-71.

18. Penchansky R, Thomas JW. The concept of access: definition and relationship to consumer satisfaction. Med Care 1981;19:127-40.

19. Rosson GD, Singh NK, Ahuja N, et al. Multilevel analysis of the impact of community vs patient factors on access to immediate breast reconstruction following mastectomy in Maryland. Arch Surg 2008;143:1076-81. discusion 81.

20. Agarwal S, Pappas L, Neumayer L, et al. An analysis of immediate postmastectomy breast reconstruction frequency using the surveillance, epidemiology, and end results database. Breast $J$ 2011;17:352-8.

21. Morrow M, Mujahid M, Lantz PM, et al. Correlates of breast reconstruction: results from a population-based study. Cancer 2005;104:2340-6.

22. Roughton MC, DiEgidio P, Zhou L, et al. Distance to a plastic surgeon and type of insurance plan are independently predictive of postmastectomy breast reconstruction. Plast Reconstr Surg 2016;138:203e-11.

23. Morrow M, Li Y, Alderman AK, et al. Access to breast reconstruction after mastectomy and patient perspectives on reconstruction decision making. JAMA Surg 2014;149:1015-21.

24. Sandelin K, King E, Redman S. Breast reconstruction following mastectomy: current status in Australia. ANZ J Surg 2003;73:701-6.

25. Greenberg CC, Schneider EC, Lipsitz SR, et al. Do variations in provider discussions explain socioeconomic disparities in postmastectomy breast reconstruction? J Am Coll Surg 2008:206:605-15.

26. Preminger BA, Trencheva K, Chang CS, et al. Improving access to care: breast surgeons, the gatekeepers to breast reconstruction. $J$ Am Coll Surg 2012;214:270-6.

27. McManus P, Sterne GD, Fatah F, et al. Immediate breast reconstruction in the West Midlands: a survey of current practice. $\mathrm{Br}$ J Plast Surg 2003;56:567-70.

28. Albornoz CR, Cohen WA, Razdan SN, et al. The impact of travel distance on breast reconstruction in the United States. Plast Reconstr Surg 2016;137:12-18.

29. Birkmeyer JD, Reames BN, McCulloch P, et al. Understanding of regional variation in the use of surgery. Lancet 2013;382:1121-9.

30. Brunet J, Sabiston CM, Burke S. Surviving breast cancer: women's experiences with their changed bodies. Body Image 2013;10:344-51.

31. Jørgensen L, Garne JP, Søgaard M, et al. The experience of distress in relation to surgical treatment and care for breast cancer: an interview study, Eur J Oncol Nurs 2015;19:612-8.

32. Rubin LR, Tanenbaum M. "Does That Make Me A Woman?": Breast Cancer, Mastectomy, and Breast Reconstruction Decisions Among Sexual Minority Women. Psychology of Women Quarterly 2011;35:401-14.

33. Alderman AK, Hawley ST, Waljee J, et al. Understanding the impact of breast reconstruction on the surgical decision-making process for breast cancer. Cancer 2008;112:489-94.

34. Chen JY, Malin J, Ganz PA, et al. Variation in physicianpatient discussion of breast reconstruction. J Gen Intern Med 2009;24:99-104.

35. Katz SJ, Lantz PM, Paredes Y, et al. Breast cancer treatment experiences of Latinas in Los Angeles County. Am J Public Health 2005;95:2225-30.

36. Lim J, Low SC, Hoe M. Breast reconstruction after mastectomy: a survey of general surgeons in Singapore. ANZ J Surg 2001;71:207-11.

37. Alderman AK, Hawley ST, Janz NK, et al. Racial and ethnic disparities in the use of postmastectomy breast reconstruction: results from a population- based study. JCO 2009;27:5325-30.

38. Tseng JF, Kronowitz SJ, Sun CC, et al. The effect of ethnicity on immediate reconstruction rates after mastectomy for breast cancer. Cancer 2004;101:1514-23.

39. Platt J, Zhong T, Moineddin R, et al. Geographic variation immediate and delayed breast reconstruction utilization in Ontario, Canada and 
plastic surgeon availability: a population-based observational study. World J Surg 2015;39:1909-21.

40. Angus J. The material and social predicaments of home: women's experiences after aortocoronary bypass surgery. Can J Nurs Res 2001;33:27-42.

41. Andsager JL, Hust SJT, Powers A. Patient-blaming and representation of risk factors in breast cancer images. Women Health 2001;31:57-79.

42. Blackstone A. "Its just about being fair" - Activism and the politics of volunteering in the breast cancer movement. Gender \& Society 2004; 18:350-68.

43. Sulik GA. Care work for the self and coping with breast cancer. Gender \& Society 2007;21:857-77.

44. Sandelowski M. Whatever happened to qualitative description? Res Nurs Health 2000;23:334-40.

45. Mackenzie NK S. Research dilemmas: paradigms, methods and methodology. Issues In Educational Research 2006;16.

46. Colorafi KJ, Evans B. Qualitative descriptive methods in health science research. HERD 2016;9:16-25.

47. Sandelowski M. What's in a name? qualitative description revisited. Res Nurs Health 2010;33:77-84.

48. Tong A, Sainsbury P, Craig J. Consolidated criteria for reporting qualitative research (COREQ): a 32-item checklist for interviews and focus groups. Int J Qual Health Care 2007;19:349-57.

49. SAGE. The SAGE encyclopedia of qualitative research methods. Los Angeles, USA: SAGE, 2008

50. Palinkas LA, Horwitz SM, Green CA, et al. Purposeful sampling for qualitative data collection and analysis in mixed method implementation research. Adm Policy Ment Health 2015;42:533-44.

51. Andersen RM, Davidson PL. Improving access to care in America: individual and contextual indicators. changing the US health care system: key issues in health services policy and management. 3rd ed. San Francisco, CA, US: Jossey-Bass, 2007: 3-31.

52. Aday LA, Andersen R. A framework for the study of access to medical care. Health Serv Res 1974;9:208-20.

53. Andersen RM. Revisiting the behavioral model and access to medical care: does it matter? J Health Soc Behav 1995;36:1-10.

54. Collins CS, Stockton CM. The central role of theory in qualitative research. Int J Qual Methods 2018;17.

55. Reeves S, Albert M, Kuper A, et al. Why use theories in qualitative research? BMJ 2008;337

56. Carter SM, Little M. Justifying knowledge, justifying method, taking action: epistemologies, methodologies, and methods in qualitative research. Qual Health Res 2007;17:1316-28.

57. Musselwhite K, Cuff L, McGregor L, et al. The telephone interview is an effective method of data collection in clinical nursing research: a discussion paper. Int J Nurs Stud 2007;44:1064-70.

58. Sturges JE, Hanrahan KJ. Comparing telephone and face-to-face qualitative interviewing: a research note. Qual Res 2004;4:107-18.

59. Sweet L. Telephone interviewing: is it compatible with interpretive phenomenological research? Contemp Nurse 2002;12:58-63.

60. Vogl S. Telephone versus face-to-face interviews: mode effect on semistructured interviews with children. Sociological Methodology 2013;43:133-77.

61. Drabble L, Trocki KF, Salcedo B, et al. Conducting qualitative interviews by telephone: lessons learned from a study of alcohol use among sexual minority and heterosexual women. Qual Soc Work 2016;15:118-33.

62. Stephens N. Collecting data from elites and ultra elites: telephone and face-to-face interviews with macroeconomists. Qual Res 2007;7:203-16.

63. Deakin H, Wakefield K. Skype interviewing: reflections of two PHD researchers. Qual Res 2014;14:603-16.

64. Carr ECJ, Worth A. The use of the telephone interview for research NT Research 2001;6:511-24.

65. Malterud K. Qualitative research: Standards, challenges, and guidelines. The Lancet 2001;358:483-8.

66. Saldana J. The coding manual for qualitative research. Singapore: SAGE publications, 2009

67. Bradley EH, Curry LA, Devers KJ. Qualitative data analysis for health services research: developing taxonomy, themes, and theory. Health Serv Res 2007;42:1758-72.
68. Clarke A. Qualitative research: data analysis techniques. Prof Nurse 1999;14:531-3.

69. Sutton J, Austin Z. Qualitative research: data collection, analysis, and management. Can J Hosp Pharm 2015;68:226-31.

70. Krefting L. Rigor in qualitative research: the assessment of Trustworthiness. American Journal of Occupational Therapy 1991;45:214-22.

71. Nowell LS, Norris JM, White DE, et al. Thematic analysis: Striving to meet the Trustworthiness criteria. International Journal of Qualitative Methods 2017;16.

72. Braun V, Clarke V. What can "thematic analysis" offer health and wellbeing researchers? Int J Qual Stud Health Well-being 2014;9:26152.

73. Braun V, Clarke V. Using thematic analysis in psychology. Qual Res Psychol 2006;3:77-101.

74. Schilt K, Westbrook L, Gender D. Doing Heteronormativity: "Gender Normals," Transgender People, and the Social Maintenance of Heterosexuality. Gender \& Society 2009;23:440-64.

75. Kearney AJ. Increasing our understanding of breast self-examination women talk about cancer, the health care system, and being women. Qual Health Res 2006;16:802-20.

76. Sivell S, Edwards A, Elwyn G, et al. Understanding surgery choices for breast cancer: how might the theory of planned behaviour and the common sense model contribute to decision support interventions? Health Expect 2011;14(Suppl 4):6-19.

77. Angus JE, Dale CM, Nielsen LS, et al. Gender matters in cardiac rehabilitation and diabetes: using Bourdieu's concepts. Soc Sci Med 2018;200:44-51.

78. Hawker GA, Wright JG, Coyte PC, et al. Differences between men and women in the rate of use of hip and knee arthroplasty. $N$ Engl $J$ Med 2000;342:1016-22.

79. Ristevski E, Regan M, Birks D, et al. A qualitative study of rural women's views for the treatment of early breast cancer. Health Expect 2015;18:2928-40.

80. Boehmer U, Linde R, Freund KM. Breast reconstruction following mastectomy for breast cancer: the decisions of sexual minority women. Plast Reconstr Surg 2007;119:464-72.

81. Rubin LR, Chavez J, Alderman A, et al. 'Use what God has given me': Difference and disparity in breast reconstruction. Psychol Health 2013;28:1099-120.

82. Comino EJ, Davies GP, Krastev Y, et al. A systematic review of interventions to enhance access to best practice primary health care for chronic disease management, prevention and episodic care. BMC Health Serv Res 2012;12:415.

83. Andermann A, Collaboration C. Taking action on the social determinants of health in clinical practice: a framework for health professionals. Can Med Assoc J 2016;188:E474-83.

84. Jones W, Elwyn G, Edwards P, et al. Measuring access to primary care appointments: a review of methods. BMC Fam Pract 2003;4:8.

85. Berk ML, Schur CL. Measuring access to care: improving information for policymakers. Health Aff 1998;17:180-6.

86. Crane R, Daniere A. Measuring access to basic services in global cities: descriptive and behavioral approaches. J Am Plann Assoc 1996;62:203-21.

87. Gulliford M, Figueroa-Munoz J, Morgan M, et al. What does 'access to health care' mean? J Health Serv Res Policy 2002;7:186-8.

88. Holland F, Archer S, Montague J. Younger women's experiences of deciding against delayed breast reconstruction post-mastectomy following breast cancer: An interpretative phenomenological analysis. $J$ Health Psychol 2016;21:1688-99.

89. Truelsen M. The meaning of 'reconstruction' within the lived experience of mastectomy for breast cancer. Couns Psychother Res 2003;3:307-14

90. Sherman KA, Harcourt DM, Lam TC, et al. BRECONDA : Development and acceptability of an interactive decisional support tool for women considering breast reconstruction. Psychooncology 2014;23:835-8.

91. Archer S, Holland FG, Montague J. 'Do you mean I'm not whole?': exploring the role of support in women's experiences of mastectomy without reconstruction. J Health Psychol 2018;23:1598-609. 